\title{
Tinnitus Retraining Therapy Protocol
}

\author{
Shi Nae Park \\ Department of Otolaryngology-HNS, College of Medicine, The Catholic University of Korea, Seoul St. Mary's Hospital, Seoul, Korea
}

이명재훈련치료 프로토콜

박 시 내

가톨릭대학교 의과대학 서울성모병원 이비인후과학교실

\begin{abstract}
A world-widely renowned therapeutic modality of tinnitus, tinnitus retraining therapy (TRT) consists of two components; directive counseling and sound therapy. Directive counseling is known as a determining factor for the successful result of TRT, which needs clinician's deep understanding of clinical and audiological characteristics of each patient with proper explanation of the theoretical backgrounds of habituation of reaction and perception. Sound therapy using environmental sound, sound generator or hearing aids depending on the patient's category also plays an important role in facilitating habituation process. Prominent tinnitus-related neuronal signal could be less stressful to the patients due to decrease in contrast of background sound and tinnitus. Convincing directive counseling combined with best sound therapy during the process of TRT will lead a successful therapeutic result. Practical protocol of TRT based on a 15 year experience in a special clinic of tinnitus will be introduced. Considering factors of TRT will also be discussed with a brief review of literature.
\end{abstract}

Key Words: Tinnitus retraining therapy, Protocol, Directive counseling, Sound therapy.

Received: February 2, 2016 / Accepted: March 10, 2016

Correspondence: Shi Nae Park, Department of Otolaryngology-HNS, College of Medicine, The Catholic University of Korea, Seoul St. Mary's Hospital, 222 Banpo-daero, Seocho-gu, Seoul 06591, Korea

Tel: +82-2-2258-6215 / Fax: +82-2-2258-1354 / E-mail: snparkmd@catholic.ac.kr

\section{INTRODUCTION}

이명재훈련치료(Tinnitus retraining therapy, TRT)는 1990 년 Jastreboff와 Hazel(1990) 등이 처음 소개한 이래 전세계의 많은 이명 크리닉에서 적용되어 그 치료 효과가 보고되면서 널 리 인정받고 있는 이명 치료법이다.(Jastreboff \& Hazel, 1993; Jastreboff \& Jastreboff, 2000) 두 가지의 중요 요소인 지시적 상담(directive counseling)과 소리치료(sound therapy)로 구성 된 TRT는 감각신경성 이명 환자의 이명으로 인한 불편함의 정 도 및 청각학적 특성에 따라 카테고리를 나누어 적절한 치료방 법을 제안했다는 점에서 매우 임상적으로 유용한 방법이라 하 겠다. 1999년 이후 지난 15년간 수많은 이명 환자들을 대상으 로 TRT를 시행해 온 저자는 그간의 경험을 바탕으로 TRT를 보다 쉽게 적용할 수 있는 구체적인 방법과 TRT 적용의 과정 에서 고려해야 할 요소들을 정리하여 문헌 고찰과 함께 간략히 소개하고자 한다.

\section{TRT PROTOCOL}

\section{이명 환자의 진단 및 분류}

TRT는 이명 환자의 정확한 진단과 정신의학적 청각학적 상 태를 고려하여 카테고리를 나눈 후 적절한 지시적 상담과 소리 치료를 적용하는 치료법이다. 환자가 호소하는 이명의 양상을 통해 자각적 이명인 감각신경성 이명과 타각적 이명인 체성 소 리를 감별하고, 발생 가능한 원인이 될 수 있는 요인을 철저히 찾기 위한 다양한 청각학적 검사와 영상의학적 검사, 혈액학적 검사 등이 선행되어야 한다. 정확한 진단에 근거한 지시적 상담 치료는 이명의 발생과 지속성에 대해 큰 불안을 가진 이명 환자 의 불안을 해소 시키기 위한 TRT의 필수 요소이며, 상담을 시 행하는 치료자는 환자들이 지닌 의학적, 청각학적 의문을 모두 해소시킬 수 있는 역량을 반드시 갖추어야 한다. 많은 이명 환 자들은 이명의 발생 당시 스트레스 인자, 소음 노출, 사고 등의 유발 인자를 지니고 있으며, 이명이 지속되는 원인으로는 이 같 은 인자의 반복 노출 및 부정적인 뇌 연관 회로 형성 등이 있 
다. 따라서 치료자는 설문지, 개별 상담을 통해 이명 환자들의 이명 발생 당시 상황을 이해해야 하고 교정이 가능한 모든 유 발 인자를 제거하도록 교육해야 한다. 약물 치료 또는 수술적 치료가 필요한 타각적 이명 환자들이 자각적 이명 환자로 오진 되어 오랫동안 적절한 치료를 받지 못하는 경우도 있으므로, 이명 치료자는 환자들의 병력 청취, 문진, 이학적 검사, 영상학 적 검사 및 청각학적 검사를 정확히 시행하여 쉽게 치료될 수 있는 이명, 근육성, 혈관성 이명 및 개방성 이관증 등 타각적 이 명 환자들을 잘 진단하고, 각각의 진단에 맞는 치료를 받을 수 있도록 다양한 증례에 대한 진단과 치료적 접근법 역시 알고 있어야 한다.(Bryce \& Morrison, 1998; Lee et al., 2012; Park et al., 2013; Poe, 2007; Yoo et al., 2014) 달팽이관과 청신경계 및 대뇌 여러 신경계에서 기원한 감각신경성 이명으로 진단된 환자는 이명 설문지를 통해 환자가 느끼는 이명의 불편감, 영향 을 정확히 파악하고, 동반된 난청이나 청각과민증에 따라 적절 한 TRT를 시행하게 된다. 이명으로 인한 불편감과 영향이 심각 하지 않는 환자인 카테고리 0에서부터 난청이 동반된 카테고리 2, 청각과민증을 동반한 카테고리 3 4 환자에 따라 감각신경 성 이명 환자를 나누고 각각의 카테고리에 따라 지시적 상담 치료와 함께 소리 치료를 시행하게 된다(Table 1).

\section{지시적 상담 치료(Directive counseling)}

지시적 상담 치료는 TRT 과정에서 가장 핵심이고 치료 효과 를 결정짓는 중요한 요소이다. 효과적인 상담 치료를 위해서는 대상자인 환자의 이명에 대한 정확한 진단, 청각학적 특성이 필 수적이다. 특히 이명 환자들이 흔히 동반하는 불안, 우울, 스트 레스 및 불면증에 대한 정신의학적 평가를 여러 방법을 통해 함께 시행할 필요가 있다. 이명 설문지 외에 우울, 스트레스, 불 면증을 확인하는 정신의학적 설문지를 통해 이명 환자들의 상 태를 파악하는 것은 상담치료를 포함한 이명의 치료 전 과정에 매우 유용하다. 청각과민, 난청, 이명의 발생과 관련된 갑상선 호르몬이나 스트레스 호르몬 등의 측정(Kim et al., 2014) 또한 진단적 가치 뿐만 아니라 이명 환자의 지시적 상담 및 치료 전 과정에서 환자의 의학적 상태를 파악하는데 유용하게 활용될 수 있으며, 향후 이명 환자들의 스트레스 및 정신의학적 상태 를 보다 용이하게 파악하기 위한 바이오마커(Biomarker)의 개
발이 다양한 연구를 통해 이루어질 필요가 있다. 이명 치료자 는 환자 개개인의 이명 유발 인자와 악화 인자를 찾아 기록하 고 이해할 필요가 있으며, 동반된 난청과 청각과민증 여부를 다 양한 청각학적 검사를 통해 반드시 확인해야 한다. 상담시에는 환자들에게 청력 검사 결과를 보여주면서 이명 발생의 원인으 로서의 난청과 중추 청각계에서 일어나는 패턴 인식(pattern recognition) 등 이명 발생 및 강화의 과정에 대한 이해를 돕도 록 한다. 이음향방사 검사에서의 외유모세포 반응 저하 소견이 나 청성뇌간유발반응 검사에서의 이상 소견 유무를 확인하는 과정 역시 이명 발생의 원인과 관련한 과학적인 지식 제공을 통해 환자들이 지닌 잘못된 정보나 불안을 불식시키는데 매우 중요한 역할을 한다.

지시적 상담치료는 $1: 1$ 개인 치료를 원칙으로 하지만 최근 소규모의 그룹 상담치료도 유용하다고 보고되고 있다. 저자 역 시 TRT 초기에는 $1: 1$ 개별 상담치료를 원칙적으로 시행하였으 나 최근 연구를 통해 소규모 그룹 지시적 상담 치료의 효과가 1 : 1 상담치료 효과와 차이가 없음을 확인하고(Park et al, 2013) 보 다 많은 이명 환자들이 TRT를 받을 수 있도록 소규모 그룹 상 담치료를 시행하고 있다. 지시적 상담은 무엇보다 환자들에게 이명이 생리적으로도 발생할 수 있는 소리임을 이해시키는 과 정이 중요하고, 적절한 예시와 과학적 근거를 소개함으로써 이 명 환자들이 지닌 이명 발생 관련 잘못된 사고와 정보를 교정 하는데 역점을 두어야 한다. 더불어 이명 발생의 신경생리학적 모델(Figure 1)을 충분히 이해시키고 다음에 소개하게 될 소리 치료의 필요성, 방법, 효과를 설명함으로써 앞으로 TRT 전 과 정에 환자들이 순응할 수 있도록 유도해야 하며, 충분한 이해

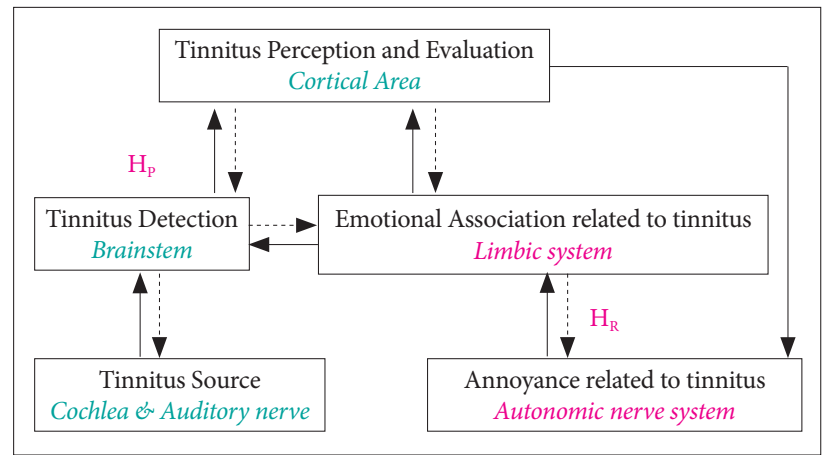

Figure 1. Neurophysiological model of tinnitus.

Table 1. Categorization of patients for TRT

\begin{tabular}{cccccl}
\hline Grade & Hyperacusis & Kindling & Hearing loss & Impact & Treatment \\
\hline 0 & - & - & - & Low & Counseling \\
1 & - & - & - & High & SG, mixing point \\
2 & - & - & NR & High & HA, env. Sound \\
3 & + & - & NR & High & SG, over-threshold \\
4 & + & + & High & SG, sub-threshold, lowly \\
\hline
\end{tabular}

SG: sound generator, HA: hearing aid, NR: not relevant 
를 위해 많은 경우 30 분이상의 상담치료 시간이 소요된다.

지시적 상담이 효과적으로 이루어지면 이명 환자들은 더 이 상 이명 발생과 관련한 불안증을 호소하지 않게 되며, 시상변 연부와 교감신경계의 과반응과 관련된 이명에 대한 신체 반응 의 습관화(Habituation of reaction, HR)가 효과적으로 이루어 질 수 있다.

\section{소리 치료(Sound therapy)}

이명에 대한 소리치료는 기본적으로 날카롭고 자극적인 이 명관련신경신호를 듣게 됨으로써 환자들이 느끼는 불안감을 최소화하고자 배경 소리(background sound)를 증폭시켜 신호 대잡음비(signal to noise ratio, SNR)을 감소시키는 것을 목적 으로 한다. 이를 위해 청각 손실 및 청각과민증이 없는 이명 환 자들(카테고리 0 및 1)에게는 이명의 불편감의 정도와 영향에 따라 환경음 또는 백색 잡음을 주로 하는 소리치료기를 혼합점 (mixing point) 수준으로 들려주는 소리치료를 시행한다. 난청 이 동반된 이명 환자에게 보청기 처방(Trotter \& Donaldson, 2008)이 큰 도움을 주며, 최근 보고된 중이이식술(Seo et al., 2015), 인공와우이식술(Kim et al., 2013) 등의 청각재활치료 효 과 역시 이명의 감소에 도움을 준다고 알려져 있어 소리치료의 방법으로 고려할 수 있다. 따라서 난청이 동반된 카테고리 2 이 명 환자의 경우 환자의 의학적, 청각학적 상태를 고려한 가장 적절한 청각재활치료를 찾아 적용하는 소리치료 선택 과정이 이명의 치료에 매우 중요하다. 청각과민증을 동반한 이명 환자 들(카테고리 3 및 4)은 보다 적극적인 소리 치료가 필요하다. 청 각과민증 환자들은 외부 소리를 피하는 습성을 지니고 있어 늘 조용한 곳을 찾게 되고 이로 인해 청각회로의 민감도가 더욱 높 아지는 현상이 발생하며, 이명 신호음 또한 강해 습관화가 일어 나기 매우 어려운 특성을 지닌다. 따라서 청각과민증 환자의 경 우 초기부터 지시적 상담과 함께 양측 귀에 소리 발생기를 처방 하여 아주 낮은 소리부터 점차 크기를 높여가며 듣게 하는 소리 치료 과정이 보다 적극적으로 필요하며, 이를 통해 청각과민증 과 이명 인식의 습관화(Habituation of perception, HP)가 유도 되어 TRT 치료의 효과를 높이고 치료 기간을 단축할 수 있다.

\section{$\mathrm{TRT}$ 추적 관찰}

TRT의 추적 관찰은 3 6개월 간격으로 최소한 2년까지 시행 할 것을 권한다. 장기적이고 정기적인 추적 관찰 기간 동안 이명 이 줄어들고 청각이 유지되는 것을 설문지, 청각학적 검사 등을 통해 확인하고 환자들의 불안증을 지속적으로 간단한 상담 치 료를 통해 불식시킬 필요가 있다. 특히 이명도 검사에서 이명 주 파수, 크기, 청각과민증을 확인하는 불쾌역치검사에서의 변화 를 확인하고, 환자에게 확신(reassurance)시킴과 동시에 소리 치
료기인 소리발생기, 보청기의 점검, 변형, 적합성 검사 등을 통해 이명 환자의 치료 전 과정에 치료자가 적극적으로 개입하는 것 이 TRT의 효과를 증대시키는데 매우 중요한 요소라 할 수 있다.

\section{CONCLUSION}

이명은 과학적인 평가와 적절한 치료법을 적용하는 전문가 를 통해 치료될 수 있는 증상이다. TRT는 별다른 부작용 없이 좋은 치료 성적을 지닌 이명 치료의 한 방법으로 높은 유병률 을 지닌 이명 환자의 치료에 분명 큰 도움을 줄 수 있다. 따라서 본 논고에서 소개한 프로토콜을 기본으로 TRT가 보다 많은 이명 환자들의 치료 방법으로 적용될 수 있기를 바란다.

중심 단어 : 이명재훈련치료·프로토콜·지시적 상담·소리 치료.

\section{REFERENCES}

Bryce, G. E. \& Morrison, M. D. (1998). Botulinum toxin treatment of essential palatal myoclonus tinnitus. Journal of Otolaryngology-Head and Neck Surgery, 27, 213-216.

Jastreboff, P. J. (1990). Phantom auditory perception (tinnitus): mechanisms of genereation. Neuroscience Research, 8, 221-254.

Jastreboff, P. J. \& Hazel, J. W. P. (1993). A neurophysiological approach to tinnitus: clinical implications. British Journal of Audiology, 27, 1-11.

Jastreboff, P. J. \& Jastreboff, M. M. (2000). Tinnitus retraining theapy (TRT) as a method for treatment of tinnitus and hyperacusis patients. Journal of the American Academy Audiology, 11, 162-177.

Kim, D. K., Bae, S. C., Park, K. H., Jun, B. C., Lee, D. H., Yeo, S. W., et al. (2013). Tinnitus in patients with profound hearing loss and the effect of cochlear implantation. European Archives of Oto-Rhino-Laryngology, 270, 1803-1808

Kim, D. K., Chung, D. Y., Bae, S. C., Park, K. H., Yeo, S. W., \& Park, S. N. (2014). Diagnostic value and clinical significance of stress hormones in patients with tinnitus. European Archives of Oto-Rhino-Laryngology, 271 (11), 2915-2921.

Lee, G. H., Bae, S. C., Jin, S. K., Park, K. H., Yeo, S. W., \& Park, S. N. (2012). Middle ear myoclonus associated with forced eyelid closure in children: diagnosis and treatment outcome. Laryngoscope, 122, 2071-2075.

Park, S. N., Bae, S. C., Lee, K. H., Song, J. N., Park, K. H., Jeon, E. J., et al. (2013). Clinical characteristics and therapeutic response of objective tinnitus due to middle ear myoclonus: a large case series. Laryngoscope, 123, 2516-2520

Park, S. N., Base, S. C., Kim, D. K., Park, Y. S., Yeo, S. W., \& Park, S. Y. (2013). Small-group counseling in a modified tinnitus retraining therapy for chronic tinnitus. Clinical and Experimental Otorhinolaryngology, 6, 214-218.

Poe, D. S. (2007). Diagnosis and management of the patulous eustachian tube. Otology and Neurotology, 28(5), 668-677.

Seo, Y. J., Kim, H. J., Moon, I. S., \& Choi, J. Y. (2015). Changes in tinnitus after middle ear implant surgery: comparisons with the cochlear implant. Ear and Hearing, 36(6), 705-709.

Trotter, M. I. \& Donaldson, I. (2008). Hearing aids and tinnitus therapy: a 25-year experience. The Journal of Laryngology and Otology, 122(10), 1052-1056.

Yoo, B. J., Kim, H. M., Jin, S. K., \& Park, S. N. (2014). Therapeutic efficacy of angiocatheter insertion surgery in the bony orifice of patulous Eustachian tube. Korean Journal of Otorhinolaryngology-Head and Neck Surgery, 57, 54-60. 